\title{
Bismuth-based triple therapy with bismuth subcitrate, metronidazole and tetracycline in the eradication of Helicobacter pylori: A randomized, placebo controlled, double-blind study
}

\author{
Sander Veldhuyzen van Zanten $\mathrm{MD}^{1}$, Alain Farley $\mathrm{MD}^{2}$, Norman Marcon $\mathrm{MD}^{3}$, Raymond Lahaie $\mathrm{MD}^{4}$, \\ André Archambault MD ${ }^{5}$, Richard Hunt $\mathrm{MD}^{6}$, Robert Bailey $\mathrm{MD}^{7}$, David Owen MD ${ }_{5}^{8}$, Jean Spénard PhD ${ }^{9}, 10$, \\ Alan Stiglick PhD ${ }^{11}$, Nick Aimola MSc ${ }^{12}$, Patrick Colin $\mathrm{PhD}^{5}$
}

S Veldhuyzen van Zanten, A Farley, N Marcon, et al. Bismuthbased triple therapy with bismuth subcitrate, metronidazole and tetracycline in the eradication of Helicobacter pylori: A randomized, placebo controlled, double-blind study. Can J Gastroenterol 2000;14(7):599-602.

OBJECTIVE: To determine the rate of Helicobacter pylori eradication following bismuth-based triple therapy with colloidal bismuth subcitrate, tetracycline hydrochloride and metronidazole. PATIENTS AND METHODS: One hundred and eleven patients were randomly assigned, in a two to one ratio, to colloidal bismuth subcitrate $120 \mathrm{mg}$ qid plus metronidazole $250 \mathrm{mg}$ qid plus tetracycline $500 \mathrm{mg}$ qid (Gastrostat), or matching placebo tablets and capsules for 14 days. Presence or absence of $H$ pylori was documented by histology at entry and at least 28 days after treatment. Patients had dyspeptic symptoms with or without a history of peptic ulcer. Patients with any previous attempt(s) at eradication of H pylori, who used bismuth, antibiotics, $\mathrm{H}_{2}$ receptor antagonists or proton pump inhibitors in the previous four weeks were excluded.
RESULTS: Fifty-three of 59 (90\%) patients on bismuth-based treatment and only one of 35 (3\%) on placebo achieved eradication by per protocol analysis. Fifty-three of $65(82 \%)$ patients on bismuth-based treatment achieved eradication, while only two of $34(5 \%)$ achieved eradication on placebo by intention to treat analysis. Eradication rates for bismuth-based treatment across sites ranged from $83 \%$ to $100 \%$. Only two patients in the bismuthbased treatment group (4\%) and one in the placebo group (3\%) discontinued treatment because of adverse events.

CONCLUSIONS: Colloidal bismuth subcitrate plus metronidazole plus tetracycline, given in the doses studied for 14 days, is safe and highly effective against $H$ pylori infection and would be appropriate as a first-line therapy for eradication.

Key Words: Bismuth; Helicobacter pylori; Metronidazole; Tetracycline; Triple-therapy

Pour le résumé, voir page suivante

${ }^{1}$ Queen Elizabeth II Health Sciences Centre, Halifax, Nova Scotia; ${ }^{2}$ Centre de Gastro-Entérologie et d'Endoscopie de Montréal, Montréal, Quebec;

${ }^{3}$ The Wellesley Hospital, Toronto, Ontario; ${ }^{4}$ Centre Hospitalier de l'Université de Montréal, Pavillon St-Luc, Montreal, Quebec; ${ }^{5}$ Hôpital

Maisonneuve-Rosemont, Montréal, Quebec; ${ }^{6}$ McMaster University, Hamilton, Ontario; ${ }^{7}$ Hys Centre, Edmonton, Alberta; ${ }^{8}$ Vancouver

General Hospital, Vancouver, British Columbia; ${ }^{9}$ Axcan Pharma Inc, Mont-Saint-Hilaire, Quebec; ${ }^{10}$ Faculty of Medicine, Department of

Pharmacology, University of Montreal, Montreal, Quebec; ${ }^{11}$ SkiyLick $\& 5$ Associates; ${ }^{12}$ Aimola Eु Associates Inc, Mississauga, Ontario

Correspondence: Dr Sander Veldhuyzen van Zanten, Division Of Gastroenterology, Dalhousie University, Centennial Building, Room 928, Queen

Elizabeth II Health Sciences Centre, 4th Floor, Halifax, Nova Scotia B3H 2 Y9.

Telephone 902-473-2397, fax 902-473-4406, e-mail gisxm@qe2-hsc.ns.ca

Received for publication March 3, 1999. Accepted January 26, 2000 


\section{Thérapie triple à base de bismuth avec du sous-citrate de bismuth, du métronidazole et de la tétracycline pour l'éradication de Helicobacter pylori : une étude à double insu, comparative avec placebo et randomisée}

OBJECTIF : Déterminer le taux d'éradication de Helicobacter pylori après une triple thérapie à base de bismuth avec du sous-citrate de bismuth, du chlorhydrate de tétracycline et du métronidazole.

PATIENTS ET MÉTHODES : Cent onze patients ont été assignés au hasard dans une proportion de 2 contre 1 à un groupe de traitement avec $120 \mathrm{mg}$ de sous-citrate de bismuth colloïdal quatre fois par jour plus $250 \mathrm{mg}$ de métronidazole quatre fois par jour plus $500 \mathrm{mg}$ de tétracycline (Gastrostat) ou dans un groupe de traitement placebo par comprimés et capsules appariés pendant 14 jours. La présence ou l'absence de Helicobacter pylori a été documentée par un examen histologique à l'inclusion des patients dans l'étude et au moins 28 jours après le traitement. Les patients souffraient de dyspepsie avec ou sans ulcère gastro-duodénal. Les patients qui avaient fait l'objet d'une ou plusieurs tentatives d'éradication de Helicobacter pylori antérieurement, qui avaient utilisé du bismuth, des antibiotiques, des antagonistes des récepteurs $\mathrm{H}_{2}$ ou des inhibiteurs de la pompe à protons dans les quatre semaines précédentes ont été exclus de l'étude.

RÉSULTATS : Cinquante-trois des 59 (90\%) patients du groupe de traitement à base de bismuth, et seulement un des 34 (3\%) sont parvenus à une éradication par placebo selon une analyse par protocole. Cinquantetrois des $65(82 \%)$ patients du groupe de traitement à base de bismuth sont parvenus à une éradication, alors que deux patients seulement sur 34 (5 \%) sont parvenus à une éradication par placebo selon une analyse avec intention de traiter. Les taux d'éradication pour le traitement à base de bismuth à travers les sites allait de $83 \%$ à $100 \%$. Seulement deux patients du groupe de traitement à base de bismuth (4\%) et un du groupe placebo (3\%) ont cessé le traitement à cause d'effets indésirables.

CONCLUSIONS : Une thérapie triple avec du sous-citrate de bismuth colloïdal, du métronidazole et de la tétracycline, administrés aux doses étudiées pendant 14 jours, est sûre et très efficace contre Helicobacter pylori et serait appropriée comme traitement de première ligne pour son éradication.
$\mathrm{T}$ here is conclusive evidence that Helicobacter pylori is associated with duodenal ulcer, gastric ulcer and gastric cancer (1-3).

A meta-analysis of $H$ pylori eradication studies indicated that bismuth-based triple therapy regimens comprising bismuth, a nitroimidazole and a second antibiotic achieved eradication rates of up to $80 \%$, and that the most effective combination in this class is colloidal bismuth subcitrate, metronidazole and tetracycline (4). However, many of the studies included in that meta-analysis suffered from methodological weaknesses (5).

The primary objective of the present study was to determine the rate of $\mathrm{H}$ pylori eradication following therapy with colloidal bismuth subcitrate $120 \mathrm{mg}$ (as bismuth oxide) qid, metronidazole $250 \mathrm{mg}$ qid and tetracycline hydrochloride $500 \mathrm{mg}$ qid for 14 days in $\mathrm{H}$ pylori-positive dyspeptic patients with or without a history of peptic ulcer.

\section{PATIENTS AND METHODS}

This randomized, double-blind, placebo controlled, parallel group, multicentre study comprised H pylori-positive patients with dyspepsia. The local Ethics Committee of each of the participating centres approved the study.

Subjects were selected from patients scheduled to undergo gastroscopy. Males or females, aged 18 to 75 years, positive for $\mathrm{H}$ pylori by histology at entry and presenting with symptoms of dyspepsia were eligible after giving informed written consent.

Exclusion criteria were macroscopic esophagitis; active duodenal or gastric ulcer within three months of enrollment; previous gastric surgery; dysphagia; vomiting; hematemesis; melena; recent documented gastrointestinal bleeding; irondeficiency anemia; pregnancy; inability to abstain from alcohol; significantly impaired renal or hepatic function; contraindication to the use of bismuth, metronidazole or tetracycline; chronic use of nonsteroidal anti-inflammatory drugs
(NSAIDs); use of antibiotics in the 30 days before enrollment; regular use of bismuth compounds in the past 30 days; a previous attempt to eradicate $H$ pylori infection; and use of antiulcer drugs (including $\mathrm{H}_{2}$ receptor antagonists or proton pump inhibitors) during the seven days preceding enrollment.

During endoscopy, two biopsies were taken from the antrum and two from the body. They were placed in $10 \%$ formalin in individual containers and sent to the central study pathologist, who was blinded to the treatment received by the patients. All sections were stained using a special silver stain for Helicobacter organisms as well as the routine hematoxylin and eosin stain (6).

If $H$ pylori was detected on site by rapid urease test, the patient was randomly assigned to active or matching placebo treatment by using a two to one ratio of active drugs or placebo. This result had to be confirmed by the presence of $\mathrm{H}$ pylori on at least one of the four histology slides to confirm the patient's validity. Active treatment comprised colloidal bismuth subcitrate $120 \mathrm{mg}$ qid, metronidazole $250 \mathrm{mg}$ qid and tetracycline hydrochloride $500 \mathrm{mg}$ (Gastrostat, Axcan Pharma, Canada) qid for 14 days. Subjects self-administered the study drugs, provided in a blister pack, four times daily on an empty stomach, $1 \mathrm{~h}$ before meals and at bedtime for 14 days. Subjects were instructed not to take milk or other dairy products, or antacids within $2 \mathrm{~h}$ of taking the study medications.

Within four days of completion of therapy, physical examination and clinical laboratory tests were repeated and adverse events recorded. Not less than 28 days after the end of treatment, patients returned for a repeat endoscopy and four biopsies were taken to verify the presence or absence of $\mathrm{H}$ pylori. Eradication was defined as the absence of $\mathrm{H}$ pylori on all histology slides taken at least four weeks after the end of treatment.

All medications for dyspepsia were prohibited throughout the study, as were NSAIDs and acetylsalicylic acid. The oc- 
casional use of acetaminophen was, however, permitted. The use of antacids was allowed as rescue medication if the dyspepsia symptoms were severe.

Patients enrolled in this study were a priori advised to refrain from alcohol during the two-week treatment period. Female patients using oral contraceptives were informed about the risk of interaction between tetracyline and oral contraceptives, and advised to use an additional means of contraception. Patients were also warned to avoid exposure to direct sunlight and/or ultraviolet light during the twoweek treatment period because of the photosensitivity effect of tetracycline.

The sample size of 62 subjects in the active treatment group was based on the following assumptions: expected eradication rate of BMT $80 \%$ and of placebo $0 \%$, alpha error $5 \%$ and length of the confidence interval $95 \%$.

The primary analysis was a per protocol (PP) analysis and included all patients with positive histology at entry and evaluable histology four weeks later. The intention to treat (ITT) analysis included all patients with positive histology at entry who met the inclusion/exclusion criteria, except for three patients who completed the study with all procedures performed successfully but whose final histology slides were lost by the carrier between the study site and the central laboratory. These three patients were not considered in any analysis.

A posteriori exploratory analysis was done on the influence of ulcer type on eradication rate.

\section{RESULTS}

One hundred and eleven patients were randomly assigned to the study medication. Four were found to be $H$ pylori-negative at entry, the poststudy slides were lost during transportation for two patients, the prestudy slides were lost during transportation for one patient and one patient was entered in violation of the inclusion criteria (found to be pregnant) and her treatment was interrupted after one dose, leaving 103 patients evaluable by ITT analysis. Three more patients withdrew because of adverse events, five were lost to follow-up and one withdrew voluntarily, leaving 94 patients evaluable by PP analysis.

Of the 103 patients evaluable by ITT analysis, 65 received BMT therapy and 38 received placebo. Fifty-three (81.5\%) patients on BMT achieved $H$ pylori eradication. The $95 \%$ confidence interval of the rate of eradication ranged from $76.7 \%$ to $86.4 \%$ by ITT analysis.

Of the 94 patients evaluable by PP analysis, 59 received the BMT therapy and 35 received placebo. Their demographics are presented in Table 1. Fifty-three of 59 patients (90\%) receiving BMT achieved eradication of $H$ pylori infection, while only one of the 35 patients (3\%) receiving placebo did $(\mathrm{P}<0.0001)$. The $95 \%$ confidence interval of the rate of eradication by BMT ranged from $82 \%$ to $98 \%$. The individual eradication rates by study centre were $83 \%, 89 \%$, $91 \%, 100 \%, 100 \%, 100 \%$ and $100 \%$.

Thirty-six patients $(63 \%)$ receiving active BMT and twenty-four $(69 \%)$ receiving placebo had a history of pre-
TABLE 1

Demographics for the efficacy analysis of Helicobacter pylori eradication

\begin{tabular}{lccc}
\hline Variable & $\begin{array}{c}\text { Active drug } \\
(\mathbf{n = 5 9 )}\end{array}$ & $\begin{array}{c}\text { Placebo } \\
(\mathbf{n = 3 5 )}\end{array}$ & $\mathbf{P}$ \\
\hline Age (years), mean \pm SE & $49.8 \pm 1.8$ & $47.5 \pm 1.9$ & $\mathrm{NS}$ \\
Height (cm), mean \pm SE & $167.9 \pm 1.4$ & $169.7 \pm 1.7$ & $\mathrm{NS}$ \\
Weight (kg), mean \pm SE & $72.3 \pm 2.1$ & $75.3 \pm 2.6$ & $\mathrm{NS}$ \\
Men/women & $28 / 29$ & $25 / 10$ & 0.0503 \\
History of ulcer & & & \\
$\quad$ Yes & 36 & 24 & \\
$\quad$ No & 21 & 11 & NS \\
Type of ulcer & & & \\
$\quad$ Gastric & 16 & 9 & \\
$\quad$ Duodenal & 13 & 7 & \\
$\quad$ Unspecified & 7 & 8 & NS \\
\hline
\end{tabular}

NS Not significant

vious ulcer or showed deformity of the duodenal cap in keeping with previous ulcer. In patients receiving BMT, there was no statistically significant difference in eradication rates between patients with a history of ulcer $(91.7 \%)$ and those without $(85.7 \%)$ (either gastric, duodenal or unspecified; $\mathrm{P}=0.659$ ) or between site of ulcer (gastric [87.5\%] versus duodenal [92.3\%]; $\mathrm{P}=1.000$ ).

Three patients violated the protocol. One stopped treatment after 13 days but was reported as completing the study by the investigator. The infection was successfully eradicated in this patient. One took a single dose of diclofenac on day 9 of treatment; the infection was successfully eradicated in this patient. The third patient received ketoprofen during the whole 14-day period of BMT. The infection was not cured in this patient, who showed presence of an active ulcer at the last visit. All three patients were included in both analyses.

Three patients discontinued study drugs because of adverse events: two $(4 \%)$ in the BMT group and one $(3 \%)$ in the placebo group. One patient withdrew after 2.5 days (10 doses) of treatment with BMT because of nausea and lightheadedness; another withdrew after 4.5 days (18 doses) of treatment with BMT because of bloating and tiredness; and the third withdrew after three days (12 doses) of treatment with placebo because of heartburn, diarrhea, abdominal pain and dizziness.

Nausea (26\%), taste disturbance (18\%), heartburn $(17 \%)$, headache $(15 \%)$ and diarrhea $(11 \%)$ were the adverse events most often reported and considered related to active study medications. Dark stools (35\%) and loose stools $(18 \%)$ also were frequently reported. Elevations of alanine aminotransferase and aspartate aminotransferase were seen in some patients but were not clinically important.

\section{DISCUSSION}

The results of this study, which reports a mean, PP, overall rate of $\mathrm{H}$ pylori eradication of $90 \%$, compare favourably with those published using the same bismuth-based treatment or a similar BMT treatment. 
TABLE 2

Eradication rate of Helicobacter pylori by type of analysis

\begin{tabular}{lcc}
\hline & Intention to treat & Per protocol \\
\hline BMT therapy & & \\
Number evaluable & 65 & 59 \\
Number eradicated & 53 & 53 \\
Percentage & $81.5 \%$ & $89.8 \%$ \\
$\quad$ eradicated & & \\
$95 \% \mathrm{Cl}$ & $76.7-86.4 \%$ & $85.9-93.8 \%$ \\
Placebo & 38 & 35 \\
Number evaluable & 2 & 1 \\
Number eradicated & $5.3 \%$ & $2.9 \%$ \\
Percentage & & \\
eradicated & $1.6-8.9 \%$ & $0-5.8 \%$ \\
$95 \% \mathrm{Cl}$ &
\end{tabular}

BMT Bismuth subcitrate plus metronidazole plus tetracycline

In a multicentre, randomized trial, Thijs et al (7) compared the efficacy and safety of bismuth-based triple therapy (bismuth subcitrate $120 \mathrm{mg}$, metronidazole $250 \mathrm{mg}$ and tetracycline $250 \mathrm{mg}$ qid) versus omeprazole $40 \mathrm{mg}$ bid plus amoxicillin $1000 \mathrm{mg}$ bid - both treatments given for 14 days. Fifty-five patients ( 40 with peptic ulcer disease, 15 with nonulcer dyspepsia) received BMT. H pylori was eradicated in 96\% (52 of 54) of patients by PP and 95\% ( 52 of 55) of patients by ITT analysis. The dropout rate due to poor compliance was only $4 \%$ (two of 55 ) in the BMT group, a rate similar to that in our study. Bell et al (8) reported the results of a nonrandomized cohort study involving five different combination regimens, one of which was colloidal bismuth subcitrate $120 \mathrm{mg}$ qid, metronidazole $400 \mathrm{mg}$ tid and tetracycline $500 \mathrm{mg}$ qid given for 14 days. H pylori infection was eradicated in $89 \%$ ( 23 of 26 ) of patients. Kung et al (9) reported an $80 \%$ ( 28 of 35 ) eradication rate (ITT) following a one-week only treatment with colloidal bismuth subcitrate $120 \mathrm{mg}$ qid, metronidazole $400 \mathrm{mg}$ qid and tetracycline 500 $\mathrm{mg}$ qid. Yang et al (10) reported an 83\% (55 of 66) eradication rate (ITT) after a two-week treatment with bismuth subcitrate qid, metronidazole $250 \mathrm{mg}$ qid and tetracycline $500 \mathrm{mg}$ qid. Kim et al (11) reported an $88 \%$ (45 of 51) eradication rate (ITT) after a one-week treatment with colloidal bismuth subcitrate $120 \mathrm{mg}$ qid, metronidazole $250 \mathrm{mg}$ qid and tetracycline $500 \mathrm{mg}$ qid.

If the results of these five trials are pooled, the overall ITT eradication rate is $88 \%$ (203 of 232 ).

Unge (12) reported a meta-analysis on 56 treatment arms involving 2956 patients treated with bismuth-based therapy using bismuth (any salt), tetracycline and a nitroimidazole. H pylori infection was cured in 2326 (79\%) patients. This result, which was slightly lower than ours, likely occurred because different doses and treatment durations were included in the analysis.

In this study, resistance to metronidazole was not assessed. The reported prevalence of metronidazole resistance in Canada is about 33\% (13). Our results demonstrated that, with the limitation of not having assessed metronidazole resistance, BMT achieved a 90\% cure rate.

Three of the most often reported adverse events were expected because taste disturbance and nausea are known adverse effects of metronidazole, and diarrhea is a known adverse effect of tetracycline. Adverse events were rarely a reason to discontinue treatment and were limited in time to the period of treatment. Moreover, no serious adverse event or clinically significant laboratory abnormalities were reported in the trial.

\section{CONCLUSIONS}

BMT treatment for 14 days at the doses described here is highly effective against $\mathrm{H}$ pylori, with an overall PP eradication rate of $89.5 \%(95 \% \mathrm{CI} 81.5 \%$ to $97.5 \%)$ when metronidazole resistance is not assessed. Moreover, patients with gastric ulcer, duodenal ulcer or nonulcer dyspepsia did not respond differently to treatment with BMT. Finally, the BMT treatment was safe, and the withdrawal rate due to adverse events was very low.

\section{REFERENCES}

1. Veldhuyzen van Zanten SJO, Sherman PM. Helicobacter pylori infection as a cause of gastritis, duodenal ulcer, gastric cancer and nonulcer dyspepsia: a systematic overview. CMAJ 1994;150:177-85.

2. The Eurogast Study Group. An international association between Helicobacter pylori infection and gastric cancer. Lancet 1993;341:1359-62.

3. Hansson LE, Engstrand L, Nyren O, et al. Helicobacter pylori infection: independent risk indicator of gastric adenocarcinoma. Gastroenterology 1993;105:1098-103.

4. Chiba N, Rao BV, Rademaker JW, Hunt RH. Meta-analysis of the efficacy of antibiotic therapy in eradicating Helicobacter pylori. Am J Gastroenterol 1992;87:1716-27.

5. Talley NJ. A critique of therapeutic trials in Helicobacter pylori-positive functional dyspepsia. Gastroenterology 1994;106:1174-83.

6. Vartanian RK, Leung JK, Davis Je, Kim YB, Owen Da. A novel alcianyellow-toluidine bleu (Leung) stain for Helicobacter species: a comparison with standard stains, a cost-effectiveness analysis, and supplemental utilities. Mod Pathol 1998:11;72-8.

7. Thijs JC, Van Zwet AA, Moolenaar W, Wolfhagen MJHM, ten Bokkel Huinink J. Triple therapy vs Amoxicillin plus omeprazole for treatment of Helicobacter pylori infection: a multicenter, prospective, randomized, controlled study of efficacy and side effects. Am J Gastroenterol 1996;91:93-7.

8. Bell GD, Powell KU, Burridge SM et al. Helicobacter pylori eradication: efficacy and side effect profile of a combination of omeprazole, amoxicillin and metronidazole compared with four alternative regimens. Q J Med 1993;86:743-50.

9. Kung NNS, Sung JY, Yuen WF, et al. Prospective randomized comparison of ranitidine bismuth citrate versus colloidal bismuth sub-citrate-based triple therapy for the treatment of Helicobacter pylori infection. Presented at Digestive Disease Week, New Orleans, May 16-22, 1998:A1128. (Abst 4486)

10. Yang R, Hamamoto R, Laine L. 1-week vs 2-week bismuth subsalicylatebased triple therapy for Helicobacter pylori: results of a U.S. randomized trial. Presented at Digestive Disease Week, New Orleans, May 16-22, 1998:A282. (Abst 1141)

11. Kim N, Lim SH, Lee KH, Koo MS, Song IS, Kim CY. The effect of metronidazole and clarithromycin resistance upon 7-day triple therapy of Helicobacter pylori infections in patients with duodenal ulcer in Korea. Presented at Digestive Disease Week, New Orleans, May 16-22, 1998. (Abst 0723)

12. Unge $P$. What other regimens are under investigation to treat Helicobacter pylori infection? Gastroenterology 1997;113:S131-48.

13. Lahaie RG, Gaudreau C, Tremblay C, et al. In vitro evaluation of Helicobacter pylori pretreatment antibiotic resistance and evaluation of the diffusion test. Presented at Digestive Disease Week, New Orleans, May 16-22, 1998. (Abst 4165) 


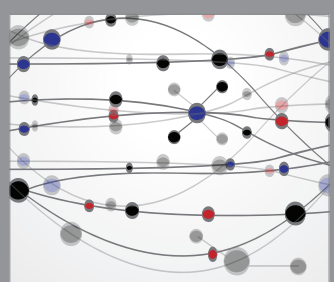

The Scientific World Journal
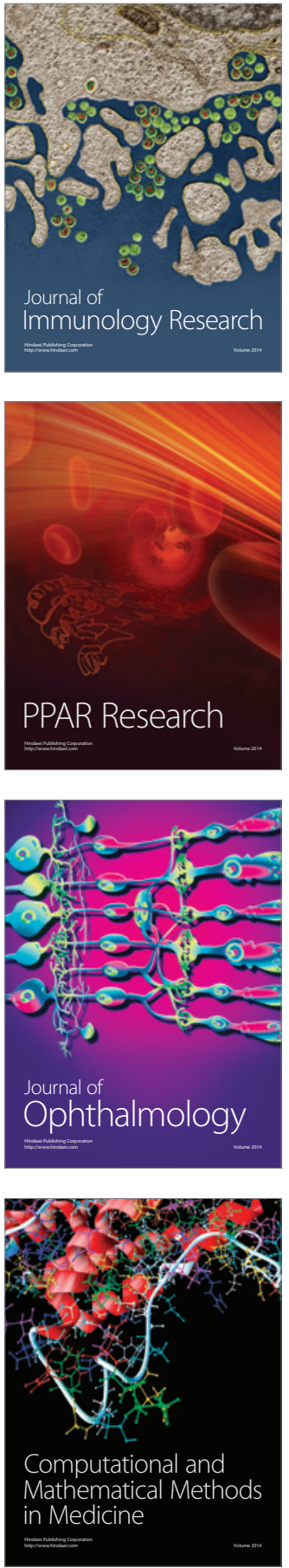

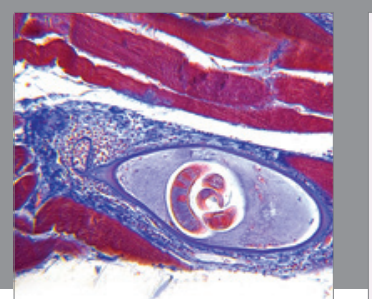

Gastroenterology Research and Practice

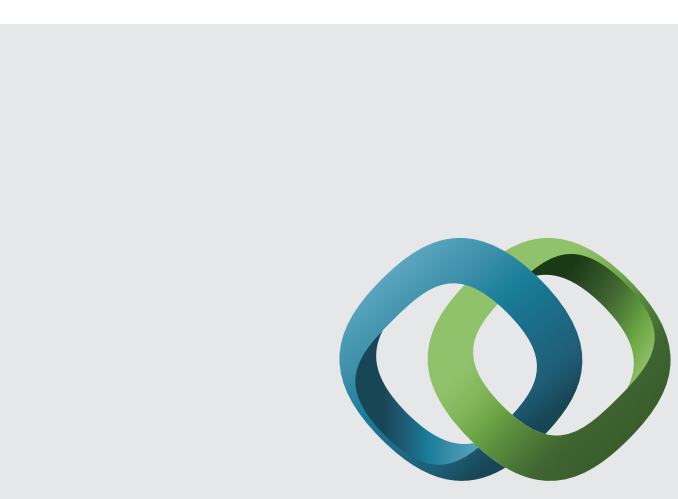

\section{Hindawi}

Submit your manuscripts at

http://www.hindawi.com
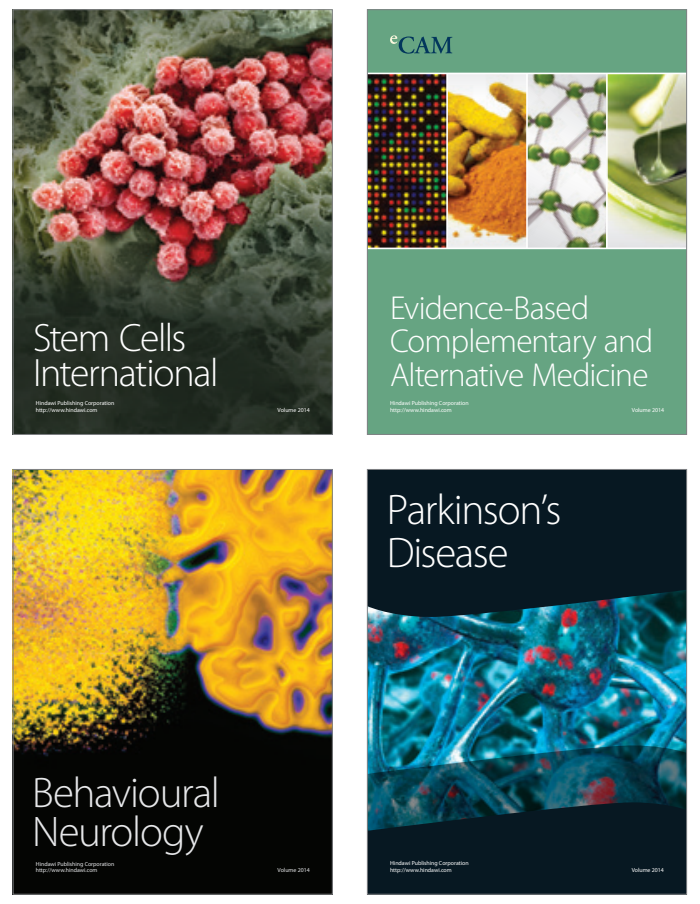
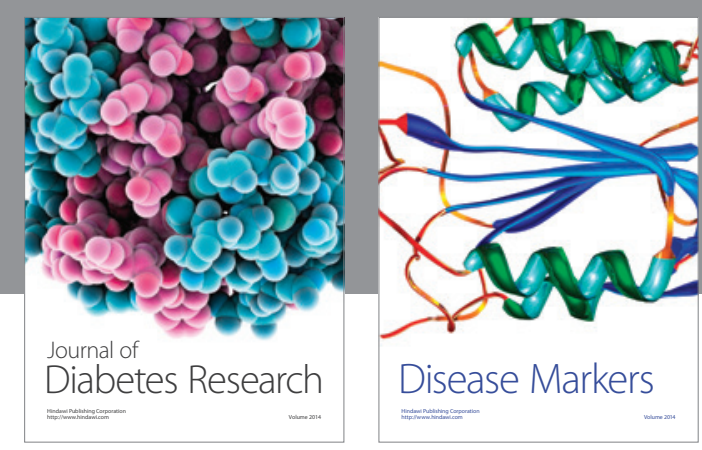

Disease Markers
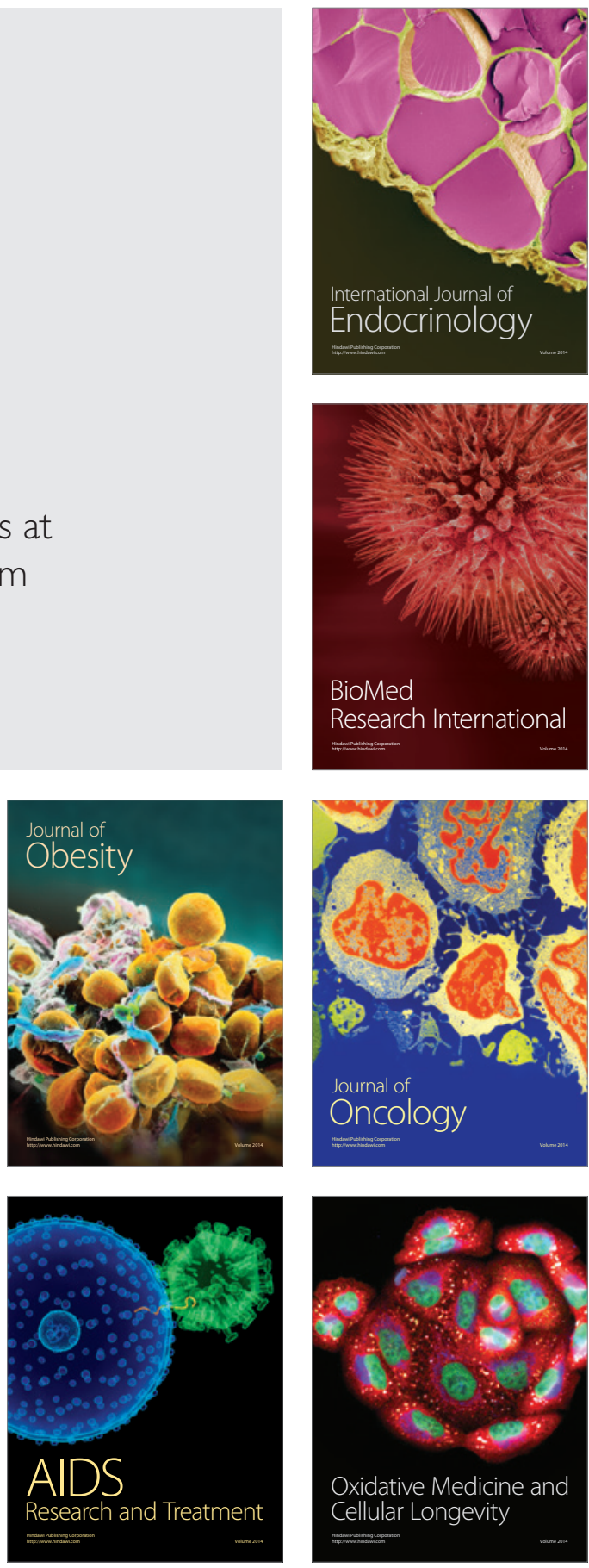